Original Research

\title{
Nurse Manager Competency Model in a Teaching Hospital
}

\section{Setiawan Setiawan, Dewi Elizadiani Suza and Farida Linda Sari Siregar}

Faculty of Nursing, Universitas Sumatera Utara, Indonesia

\begin{abstract}
Introduction: Nurse managers in carrying out their duties must have a variety of competencies, one of which is managerial competencies. A model of competency for nurse managers will assist them in shaping their roles as managers in a teaching hospital. This study aims to develop the managerial competency model for nurse managers at the teaching hospital.

Methods: The research design used in this study was action research. This research was conducted with 20 nurse managers who work at inpatient wards of the teaching hospital. Participants were selected by purposive sampling approach and have accepted to participate in the research. The data were obtained by using interview through focus groups discussions. The content analysis method was employed for analyzing the data.
\end{abstract}

Results: This study found six domains of managerial competencies of nurse managers: 1) provision of patient care (assignment methods, clinical excellence, collaborators, patient safety, evidence-based practice), 2) resource management (personnel management, information and technology management, equipment management, supplies management), 3) leadership (commitment, conflict resolution, negotiator, role model, professional mentor, initiator, motivator), 4) self and staff development (effective communication skills, interpersonal relationship skills, tridharma function of nurses), 5) customer and service orientation (team builder, customer service, quality improvement), and 6) function of preceptorships (basic teaching skills, clinical skills). These 24 fundamental competencies are rooted in caring foundation.

Conclusion: Nurse managers in teaching hospitals should possess a set of managerial competencies to perform their optimal roles in order to achieve the unit goals. This model will provide comprehensive and solid ways for nurse managers to improve their performance. Therefore, the set of nurse manager competencies needs to be standardized across the setting.

\section{ARTICLE HISTORY}

Received: March 22, 2021

Accepted: April 26, 2021

\section{KEYWORDS}

managerial competency; nurse manager; teaching hospital

\section{CONTACT}

Setiawan Setiawan

$凶$ setiawan@usu.ac.id

$\equiv$ Faculty of Nursing, Universitas Sumatera Utara, Indonesia

Cite this as: Setiawan, S., Suza, D. E., \& Siregar, F. L. S. (2021). Nurse Manager Competency Model in a Teaching Hospital. Jurnal Ners, 16(1). 81-88. doi:http://dx.doi.org/10.20473/in.v16i1.26032

\section{INTRODUCTION}

The nurse manager plays a very important role in the management of services in the hospital. These roles can be seen from the daily operational arrangements of the ward to the achievement of the goals of the ward in particular and the goals of the hospital as a larger unit. This is in line with the statement of Furukawa and Cunha (2011) that nurse managers play an important role in health services, especially in hospitals because their duties include administrative duties, providing care and also include education and research areas while remaining focused on the quality of care. The quality of care can be maintained and even improved by nurse managers by creating and enabling excellence in nursing as part of the vital role of the nurse manager (McSherry et al., 20120).

A study conducted by Miri et al. (2014) found that first-line nurse managers have a multidimensional role. This includes three categories related to management principles: planning, organizing, and leadership, with derivatives of seventeen subcategories. In addition, Miri et al. (2014) also stated that the role of other nurse managers is related to the nursing process and standards of care which consist of three categories: interpersonal contact, information processing and decision making. These 
complex roles present a challenge for nurse managers so that they can carry them out in an effective and efficient manner

In real practice in the common hospital, there may be some nurse managers performing their roles poorly. This may be related to a lack of understanding of what a nurse manager's job is or a lack of direct experience leading a ward. Research by Feather and Ebright (2013) conducted at a community-based hospital revealed the perception of staff nurses about the weaknesses of their nurse managers. Staff nurses in Feather and Ebright's study perceived their nurse managers as being task-oriented, for example, attending meetings and scheduling staff, but did not perceive them as staff-oriented who focused on relationships, building teamwork, or identifying employees with the organization. Therefore, it is necessary to have nurse managers who adopt an authentic sustainable leadership approach to facilitate and support frontline staff to make innovation and change (McSherry et al., 2012)

In Indonesia, nurse managers in hospitals have a background with knowledge and practice in nursing management, but few have advanced educational background such as master of nursing administration. The weaknesses in carrying out the roles of nurse manager as found in Feather and Ebright's study may also be found in any hospitals. Therefore, the hospital needs to have a standard about the role and function of nurse managers to become a common reference for both nurse managers, staff nurses, and hospitals in monitoring the implementation of the roles and functions of nurse managers.

Universitas Sumatera Utara Hospital, which is located in Medan city, serves as a teaching hospital. This hospital has been operating for five years and has received the title of full accreditation from the National Hospital Accreditation Commission (KARS). Most of the nurses in this hospital are young nurse generation and still need more advanced experiences in managing nursing services on a ward as nurse managers. In addition, there is no managerial competency model in this hospital that can be used by the nurse managers. With the specific nurse manager competency model which fitted for this hospital, it is hoped that all nurse managers will quickly master this managerial competence and appropriately apply it in their daily work. This study aims to develop the managerial competence model of nurse managers at Universitas Sumatera Utara hospital which serves as teaching hospital.

\section{MATERIALS AND METHODS}

The study used an action research approach. Kemmis, McTaggart, and Nixon (2014) explained that, in conducting action research several steps of action are required: reconnaissance, planning, acting and observation, and reflection.

Data collection method used interview through focus group discussions (FGD). Voice recording and field notes were used during FGD implementation.
Each FGD lasted around ninety minutes per session. A literature review was also carried out to complement the data obtained from participants. Data analysis used content analysis approach (Polit \& Beck, 2018). The content analysis was employed as a guideline to reveal significant statements which were identified later as domain and subdomain of managerial competencies of the nurse managers, as result of codings that were made.

The process of developing the model lasts for two stages: reconnaissance stage and one action research cycle (planning, acting-observing, and reflecting phase). The reconnaissance stage was to obtain data about participant perspectives on existing nurse manager competencies. At this stage, the researchers conducted one session FGD for 90-minute. During the FGD, the head of the ward and the team head were asked about the competence of the nurse manager at the Universitas Sumatera Utara hospital. The competencies are related to nursing management, preceptorship, and leadership. There was no standard of nurse manager competency in this hospital. Therefore, it is necessary to develop a nurse manager competency model at the Universitas Sumatera Utara hospital.

The next stage was for developing a model for nurse manager competency, which consisted of planning, acting-observing, and reflecting phase. The things undertaken by researchers at the planning phase were 1) the socialization of the research program and the data collection results of the reconnaissance stage, 2) planning detailed research action plan, 3) planning the team that would participate in the formulation of the model and 4) formulating required competencies for nurse managers' competencies.

Acting and observing phase was the phase of implementing model development. Activities carried out at this phase were: 1) communication with the nursing committee related to the plan to develop the nurse manager's competency model, and 2) formulation of the nurse competency model. The researcher conducted discussions with various hospital nursing division parties, regarding 1) planning the development of the nurse manager competency model, 2) forming a team to formulate the nurse manager competency model and 3) determining participants during the research process. The first FGD was held on July 18, 2018, with all participants. The results of these discussions were: 1) all the drafting teams understood the research process, 2) the drafting team needed references as model development material, and 3) the drafting team set a meeting to formulate a model to be acceptable and applicable. The second FGD was conducted on August 8, 2018, attended by all participants. The results of the second meeting were the model draft (tentative model) which covers all input from participants and literature reviews and there were nine nurse manager competency domains. The third FGD was conducted on August 31, 2018, and the results of the discussion were: 1) all experts 
validated the feasibility of the model, 2) the experts provided input to the model draft based on expertise and experience as a nurse manager in the other hospitals, and 3) there were six competencies domains of nurse manager competencies.

The reflecting phase is the evaluation phase of the action research cycle. This phase was done by one FGD session held on October 2, 2018, attended by all participants. This last FGD was in the model finalization session and it was agreed that there were six domains with 24 managerial competencies for nurse manager competencies in the final model. The evaluation results found that, during the action research cycle, the model formulation process ran smoothly. Models still in draft form were reconceptualized as intact models.

Credibility refers to confidence in the truth of data (Lincoln \& Guba, 1985). Credibility in this study was carried out with prolonged engagement, field notes, triangulation, and member checking. Long involvement was carried out by the researchers with a two-year approach and regular meetings with the participants. Field notes were made by noting situations that occurred during the study. Triangulation was also carried out through data collection from the heads of hospital ward and head of team nurses. Member checking was done by crosschecking the data findings in the form of a matrix of domain and subdomain of managerial competencies to be read by participants to obtain objectivity of the data. Confirmability was carried out by expert checks who validated the model draft. This study was approved by the Health Research Ethics Commission of the Faculty of Nursing, Universitas Sumatera Utara and the researcher also asked the participants' approval with informed consent.

\section{RESULTS}

\section{Characteristic of the participants}

The participants in this study consisted of 20 nurses who work at the Universitas Sumatera Utara hospital. All participants were in the managerial position with almost similar educational background. The majority

\begin{tabular}{lcc} 
Table 1. Characteristics of Participants $(\mathrm{n}=20)$ \\
\hline \multicolumn{1}{c}{ Characteristic } & $\mathbf{n}$ & $\mathbf{\%}$ \\
\hline Age & 3 & 15 \\
$\quad<30$ Years Old & 17 & 85 \\
$30-40$ Years Old & & \\
Gender & 20 & 100 \\
$\quad$ Female & 0 & 0 \\
$\quad$ Male & & \\
Marital Status & 20 & 100 \\
$\quad$ Married & & \\
Graduated & 19 & 95 \\
$\quad$ Bachelor & 1 & 5 \\
$\quad$ Master & & \\
Length of work experience & 7 & 35 \\
1 - 5 years & 12 & 60 \\
6 10 years & 1 & 5 \\
\hline 10 years & & \\
\hline
\end{tabular}

participants' age was $30-40$ years old as much as 85\%. All participants were female. All participants were married. Most of the participants had graduated from bachelor nursing program (95\%). The majority of participants' length of work was 6-10 years (60\%). The characteristic of the participants are illustrated in Table 1.

\section{Nurse Manager Competency Model}

The results showed that there are six themes as main domains of nurse managerial competences with 24 subthemes as fundamental competencies). These competencies domains are (1) provision of patient care consisting of five competencies (assignment methods, clinical excellence, collaborators, patient safety, evidence-based practice); (2) resource management consisting of four competencies (personnel management, information and technology management, equipment management, supplies management); (3) leadership consisting of seven competencies (commitment, conflict resolution, negotiator, role model, professional mentor, initiator, motivator), (4) self and staff development consisting of three competencies (effective communication skills, interpersonal relationship skills, tridharma function of nurses), (5) customer and service orientation consisting of three competencies (team builder, customer service, quality improvement), and (6) function of preceptorships consisting of two competencies (basic teaching skills and clinical skills). These 24 fundamental competencies are rooted in a caring foundation.

\section{DISCUSSION}

The results showed that there were six domains of nurse managerial competence carried out by nurse managers at Universitas Sumatera Utara Hospital: provision of patient care consists of five competencies, resource management consists of four competencies, leadership consists of seven competencies, self and staff development consists of three competencies, customer and service orientation consists of three competencies), and preceptorship function consists of two competencies. Overall, a nurse manager had 24 managerial competencies.

\section{Provision of patient care}

The first competency domain that is mastered by nurse managers in this study is the provision of nursing care. This competency domain is a general competency for all front-line managers in the majority of hospitals throughout the world and is useful in managing daily nursing services in the ward. Having this basic competency makes participants more confident in ensuring the completeness of nursing administrative tasks runs smoothly (Mboineki et al., 2019). Providing nursing care to patients is done by using nursing process with systematic stages and applying management concepts. 


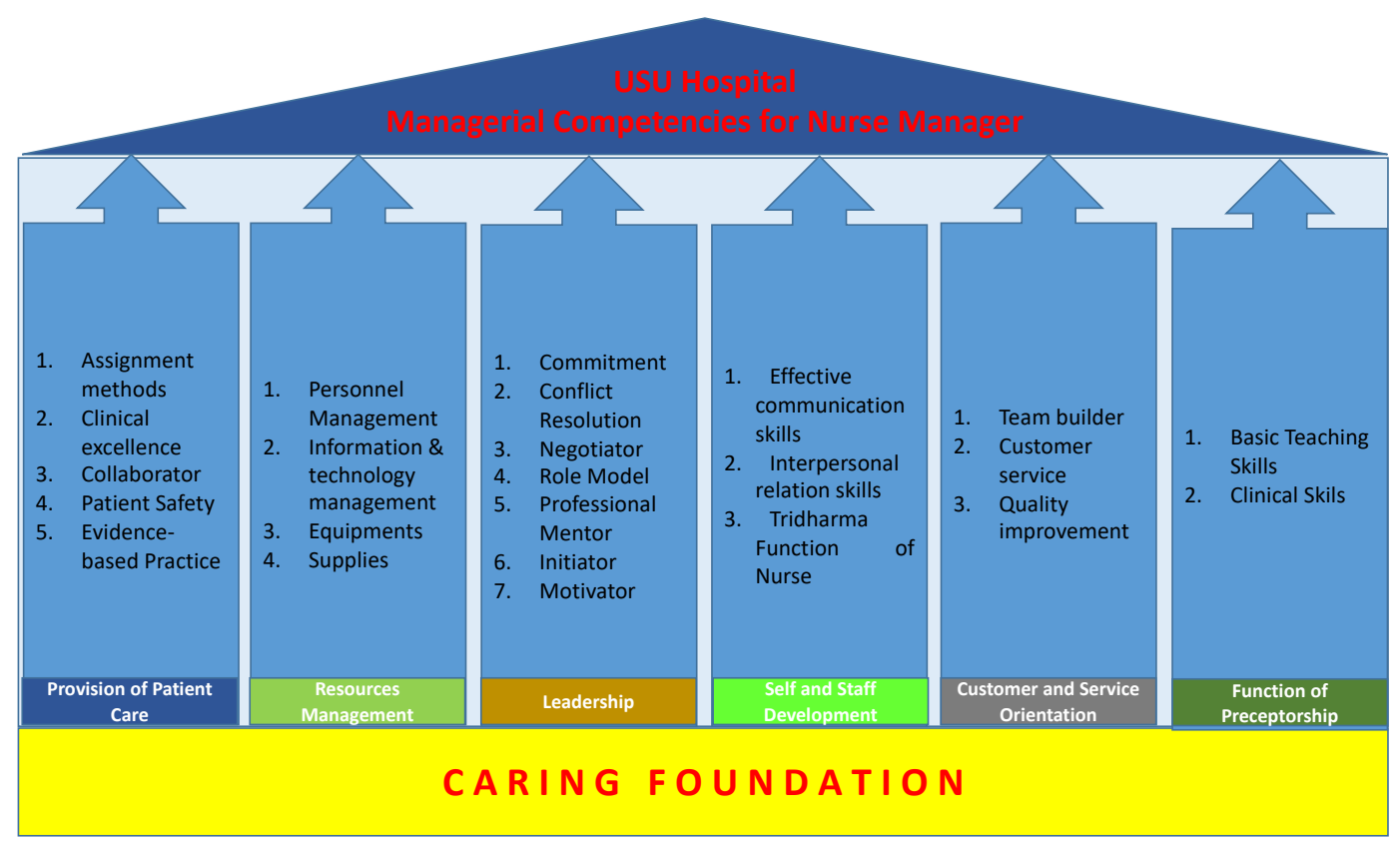

Figure 1. Proposed Nurse Manager Competence Model at Universitas Sumatera Utara Hospital

The nurse manager is required to have detailed knowledge and experience of assignment methods. There are several methods of assignment that a nurse manager can perform on a ward. The selection and implementation of an assignment method that is appropriate to the situation and conditions in a particular ward will affect the effectiveness of providing nursing care in that ward. With the right assignment method, the nurse manager can ensure that the organization and implementation of the care that the nurse will perform can achieve the predetermined goals.

Clinical excellence is a competency that a nurse manager needs to have. This competency is certainly obtained by a nurse through clinical experience as a staff nurse as well as basic and advanced training in accordance with the field of work in their respective work units. By having clinical excellence, a nurse manager can perform management functions that are more primarily related to the leading or directing function.

Collaboration is carried out to improve the quality of nursing care performed to patients. The essence is generally collaboration done clinically. Collaboration is carried out in accordance with scientific disciplines through professional communication effectively between other professions. Collaboration starts from solving problems, making decisions, formulating and implementing nursing care action plans (Elsous, Radawan, \& Mohsen, 2017). This competency is very important in organizing all nursing services in each unit with other healthcare workers. With good collaboration skills, a nurse manager works closely with other parties and ensures the achievement of the goals of the organizational unit they lead.

Patient safety is carried out as a guarantee that the patient is safe while being treated in the hospital (Motamedzadeh et al., 2019). Nursing actions are carried out based on the existing evidence base, especially in the field of nursing. The knowledge and skills of a nurse manager regarding patient safety and its implementation in the hospital are very supportive of achieving indicators of success for patient safety. This competence is very important today and in the future because the issue of patient safety is a major issue in the field of health services and is an important domain in hospital accreditation in Indonesia.

Nursing evidence-based practice is an active part of a nursing intervention based on valid evidence of nursing (Chrisman et al., 2014). In providing nursing care, it cannot be separated from the management of nursing care provided. A nurse manager who has this competence will be able to ensure that the nursing care carried out under his/her responsibility is always of the best and following the latest scientific evidence. Nurse compliance to evidence-based practice is the essential key to quality of professional health services. Increased public awareness of the quality of health services provided by health workers to patients causes hospitals to be able to provide services and maintain service quality well so as not to cause other problems (Akhu-Zaheeya, Al-Maaitah, \& Bany, 2018).

\section{Resource management}

All participants involved in this study believe that they must have competencies related to resource management. These competencies include personnel management, information technology management, equipment management, and supplies management. Planning personnel resources in a hospital must carefully consider both quantity and quality aspects. The process of creating such human resources certainly requires a long process and time. Highquality human resources certainly have high prices (Gunawan \& Aungsuroch, 2016). By having personnel 
management competence, a nurse manager will be able to manage and empower each nurse to make the optimum contribution in providing nursing services. The nurse manager can also conduct an assessment of the adequacy and suitability of the qualifications of nursing personnel within the scope of their work. In addition, the nurse manager needs to have ability to carry out coaching and in-training program in order to improve the skills and career of each nurse.

Article 12 of the Law of the Republic of Indonesia Number 44 Year 2009 concerning hospital states that a hospital must have permanent staff, including medical and medical supporting staff, nurses, pharmacists, management staff, and non-health personnel. It also mandates that the number and type of human resources must match the type and classification of the hospital. The need for highquality nurses is obtained by careful planning by the nurse manager. At one time, the knowledge and skills of staff can also be obsolete so that further education and training needs to be carried out on that person (WHO, 2009).

Information technology management is important in the assisting of nurses and nurse managers in performing their activities. The use of technology can replace the manual system in documenting nursing cares such as use of the leadership-endorsed electronic handoffs form (Staggers et al., 2012). Currently, a lot of hospitals have used a hospital information system (SIRS), including nursing care and an integrated service system, in the wards. Having the competence in managing information technology will certainly facilitate the role of nurse managers in monitoring and evaluating the implementation of nursing services in their work units. Equipment management is also considered by participants as an important managerial competency needed by a nurse manager. In the nursing unit, there are various equipment and with a certain amount and sophistication for which they have responsibility of their use and maintenance. These various tools are indispensable to support the provision of nursing care and nursing services in the ward. Consequently, the nurse manager's competence to manage this equipment becomes essential.

Just like equipment management, supplies management is also needed by nurse managers. Routine equipment that is widely used in every ward needs to be properly organized to ensure effective and efficient utilization. With this competency, a nurse manager can ensure that nursing services can run well and ensure cost-effectiveness

\section{Leadership}

Nurse managers in this study assume that leadership is a very important competency that they must master. These leadership characteristics include commitment, conflict resolution, negotiators, role models, professional mentors, initiators, and motivators. Commitment is a prerequisite that must be owned by nurse managers. A nurse manager needs a strong commitment to lead the nursing unit or division as his or her own driving force and this commitment can also be passed on to his or her subordinate staff. Conflict resolution is a competence very much needed by a nurse manager because managing a care unit involves many parties: the nurses themselves, patients, administrative staff, and other health workers. The involvement of many parties in caring for patients will certainly create dynamics that can lead to conflict. This conflict must be resolved properly so that the provision of nursing services can take place in accordance with established standards. As a negotiator, nurse managers make efforts to bridge the obstacles that can be faced by nurses with other health workers. Many collaborative activities require negotiation skills so that efforts to achieve patient care goals and care unit goals can run well and in balance. Nurse managers may use their referent power to establish their important roles working in interprofessional collaborative team in healthcare (Orchard et al., 2017). As a leader in the nursing unit or division, a nurse manager should serve as a role model. Leading several nurses who are their subordinates, must entail knowledge, skills, and attitudes that can be emulated by such subordinates. Performance as a role model can strengthen leadership style and allow a nurse manager to be more obeyed and carried out by all orders or agreements that have been made. Nurse managers can be role models with charismatic power when they are capable of integrating their managerial and professional expert knowledge along with their power (Orchard et al., 2017).

Professional mentor is a fundamental competency for a nurse manager in an effort to provide a form of continuing education for both novice and senior nurses. Novice nurses or new nurses need to receive direct education from their leaders in the form of clinical guidance or direction related to managerial aspects. Continuing education for nurses in the wards can be more effective with a direct mentoring process by the nurse manager, in addition to implementing formal education or training that nurses participate in outside the scope of nursing ward. Other important competencies possessed by nurse managers are initiators and motivators. The development of the delivery of nursing services is very dependent on the initiative of the nurse managers. Initiatives can be in the form of ideas or thoughts related to technical updates in the provision of nursing care and also to updating of service management techniques in the ward. As an initiator, the nurse manager will be more creative in producing solutions to the obstacles faced and also adaptive to changing circumstances and technological advances. As a motivator, a nurse manager is required to always be energetic and have a strong spirit. An energetic nurse manager will inspire other nurses to work. Motivation that is conveyed directly to the nurses in daily practice will also have an impact on improving performance. Providing consistent motivation combined with a good role model will 
make nurses more motivated and more enthusiastic in carrying out activities to achieve patient care goals and the goals of the nursing as an organizational unit that have been set.

These leadership characteristics are needed to ensure that all nursing duties in the ward will be effectively used by nursing staff. By having these characteristics, nurse managers will gain respect and trust from their nursing staff so that they lead the development of clinical practice in the ward (Pullen, 2016).

\section{Self and staff development}

Nurse managers state that other competencies they need to master are related to personal and staff development. This includes effective communication, interpersonal relations, and tri dharma nurse functions. As a leader in their unit, the nurse manager has an important role in developing effective communication between themselves and staff so that they can carry out their duties of nursing care.

Effective communication is a process in which a message is conveyed to a person or group of people. Effective communication is very necessary in nursing and minimizes errors in providing nursing services. Therefore, a nurse manager really needs to have effective communication skills. In carrying out their role as a manager, the nurse always communicates and ensures that the communication which takes place is effective so that messages can be received and acted upon by the staff nurse. In addition, a nurse manager also needs to ensure that the communication with other health professionals is effective so that the nurse's collaboration function runs successfully to achieve patient outcomes. The quality of communication is a vital role in the success of nursing service and nursing care undertaken and nurses are very important in communicating the actions taken (Kourkouta \& Papathanasiou, 2014).

Nurse managers are also responsible for enhancing interpersonal relationships skills both between themselves and also with other health workers. The ability to develop good relationships with staff nurses, patients and also other healthcare workers is very helpful in smoothing the efforts of nurse managers in coordinating the delivery of nursing services. Good relations can facilitate overcoming non-technical constraints that occur in the field. The better the interpersonal relationships developed by the nursing team in the unit, the better the quality of services provided to patients (Lee \& Doran, 2017). As part of the university, in this study nurse managers must also carry out the tri dharma function: providing services, conducting research, and carrying out community services. This tri dharma function is an additional role for nurse managers who work in the USU teaching hospital and characterizes them. The function of service provider is carried out by performing nursing care and nursing service for patients. Research functions can also be carried out by nurse managers at USU hospital and research funding has been provided in the form of Talenta grants supported by the university. Nurse managers can compete for research grants each year. Meanwhile, community service functions can also be carried out by nurse managers together with staff nurses. This community service activity can be in the form of activities that are internal in nature and can also be carried out outside the hospital. Generally, these community service activities are in the form of activities that are directly and indirectly related to the services provided by nurses at the hospital.

\section{Customer and service orientation}

There are three nurse manager competencies covered in the customer and service orientation domain: team builder, customer service, and quality improvement. As a team builder, nurse managers must have the ability to build a compact team in the effort to provide nursing services. This competence is important because building a team is very common in an organization. By establishing a compact team, nurse managers will have opportunity to achieve an excellent performance. They must establish a team that can work together in order to achieve the vision and mission of nursing division. The established team has to work effectively and efficiently. The resilience of a team can be seen from the coordination of the leadership and staff awareness that they are an important part of the team (Davis, 2017). Excellent team work will support the realization of good performance from nurses and also depends on the process of how individuals work together to achieve a goal (Lockhart, 2015).

Managerial competence of nurse managers is also related to the ability to implement a customer service approach in nursing services. Knowledge and skills of nurse managers in customer service aspects are expected to improve the quality of service to patients and families. The manager role plays a vital role in encouraging all nurse administrators to apply the principles of customer service in nursing services so that they can improve the quality of hospital services as a whole.

Another important managerial competence of nurse manager is the ability to carry out quality improvement. In addition to requiring the involvement of nurse managers in quality improvement efforts, they also have the ability and innovation in creating new work procedures and processes. Included in this competence is the nurse manager's ability to provide encouragement for the staff nurse to be involved in quality improvement efforts. Therefore, improved quality of services is highly dependent on the performance of nurses. Nurses who display excellent performance will be able to provide the best nursing care and will enhance nursing care (Bruyneel et al., 2015).

\section{Function of preceptorship}

The USU Hospital is a teaching hospital. Accordingly, besides providing nursing services to their 
customers, the nurse manager also functions as a preceptor for nursing students. The preceptorship function, which includes nurse managers, includes basic teaching skills and clinical skills. The involvement of nurse managers in the clinical learning process of nursing students has the consequence that they must be able to provide supervision to students in conducting nursing procedures using their basic teaching skills. They must also teach the practice of nursing services that they provide to patients and families. In addition, they must be role models both as nurses and as professional managers. Clinical skills are obtained through the implementation of nursing care during their daily practice. These skills are acquired as a career path possessed by nurses.

Through preceptorship process, nursing students, along with the nurse manager as the preceptor, will gain knowledge, skills and others aspects of being a professional nurse. The preceptorship program for undergraduate nursing students aims to shape their roles and responsibilities to be a professional nurse, by taking advantage of opportunities for development of confidence and professional socialization as well as knowledge and skills that must be acquired (Sedgwick \& Harris, 2012). The process of socialization of nursing professionalism may occur through observation and modeling the role of behavior in the learning environment (Lai \& Lim, 2012). In the implementation of the preceptorship program, the role of a preceptor is very important. A preceptor has a complex role and it requires development of key skills in order to assist students with the reality in the workplace (Ford, CourtneyPratt, \& Fitzgerald, 2013).

Implemented preceptorship by the nurse managers certainly has positive impacts. A study found that an effective preceptorship program reduced turnover by $46.5 \%$ and led medication error rate to drop 50-0\% by new nurses (Lee et al., 2009). It also influences on the nurse students as candidates for professional nurses so that to ensure competent health professionals, nurses must do so in authentic, unique and often complex situations with conflicting interests and values (Theander et al., 2016).

Finally, to complete all these competencies, nurse managers must have a strong background in caring because this teaching hospital has made caring the basis for their nursing practice. A caring foundation will facilitate nurse managers in creating a caring culture and caring environment, and also in organizing caring activities in their organization (Chen \& Liu, 2019).

Overall, the managerial model for nurse manager at USU Hospital has 24 essential competencies. This competency model is expected to be carried out by all nurse managers at USU Hospital. By mastering all the competencies contained in this model, the nurse manager can execute their functions appropriately in achieving their unit goals.

\section{Implication}

This managerial model can be applied as a standard for all nurse managers in teaching hospitals, especially USU Hospital by mastering 24 competencies so that all heads of wards as a nurse manager have the same competency and it is easy to lead change and innovate health services, especially nursing in the each ward.

\section{CONCLUSION}

The result of this study is a model of managerial competency for nurse managers who work in a teaching hospital. The model consists of six domains with 24 competencies. The existence of this model is very helpful for nurse managers in performing their roles as professional nurse managers. It is recommended that this model could be tested further so that they can be applied more extensively in teaching hospitals in Indonesia.

\section{REFERENCES}

Akhu-Zaheya, L., Al-Maaitah, R. and Bany Hani, S. (2018) 'Quality of nursing documentation: Paperbased health records versus electronic-based health records', Journal of Clinical Nursing, 27(34), pp. e578-e589. doi: 10.1111/jocn.14097.

Bruyneel L, Li B, Ausserhofer D, et al. Organization of Hospital Nursing, Provision of Nursing Care, and Patient Experiences with Care in Europe. Med Care Res Rev. 2015;72(6):643-664. doi:10.1177/1077558715589188

Chen, R \& Liu, Y. (2019). Constructing a caring training content for nurse managers: A Delphi study. Frontiers of nursing. 6,2. 161-168. DOI: 10.2478/FON-2019-0024.

Chrisman, B. J. et al. (2014) 'Exploring evidence-based practice research', (August), pp. 8-12.

Davis, C. (2017) 'Teamwork and the patient care experience', Nursing Made Incredibly Easy, 15(5), p. 4.4 doi: 10.1097/01.NME.0000521812.07765.11.

Elsous, A., Radwan, M. and Mohsen, S. (2017) 'Nurses and Physicians Attitudes toward Nurse-Physician Collaboration: A Survey from Gaza Strip, Palestine', Nursing Research and Practice, 2017, pp. 1-7. doi: 10.1155/2017/7406278.

Feather, R.A \& Ebright, P.R (2013). How staff RNs perceive nurse manager roles. Open Journal of Leadership. 2(3). 63-67. doi:10.4236/ojl.2013.23008

Ford, K., Courtney-Pratt, H. and Fitzgerald, M. (2013) 'The development and evaluation of a preceptorship program using a practice development', Australian Journal of Advanced Nursing, 30(3), pp. 5-13.

Furukawa, P, \& Cunha, I (2011). Profiles and competencies of nurse managers at accredited hospitals. Rev. Latino-Am Emfermagem. 19(1).106-14. 
Gunawan, J., \& Aungsuroch, Y. (2016) 'Managerial competence of first-line nurse managers: A concept analysis', . International Journal of Nursing Practice. 23. doi: 10.1111/ijn.12502.

Kemmis, S., McTaggart, R., \& Nixon, R. (2014). The Action Research Planner: Doing Critical Participatory Action Research. Singapore: Springer. DOI: 10.1007/978-981-4560-67-2.

Kourkouta L, Papathanasiou IV. Communication in nursing practice. Mater Sociomed. 2014;26(1):6567. doi:10.5455/msm.2014.26.65-67

Lai PK, Lim PH. Concept of professional socialization in nursing. IeJSME $2012: 6(1)$ 31-35

Lee, C. T. S. and Doran, D. M. (2017) 'The Role of Interpersonal Relations in Healthcare Team Communication and Patient Safety: A Proposed Model of Interpersonal Process in Teamwork', The Canadian journal of nursing research $=$ Revue canadienne de recherche en sciences infirmieres, 49(2), pp. 75-93. doi: 10.1177/0844562117699349.

Lee T-Y, Tzeng W-C, Lin C-H \& Yeh M-L. Effects of a preceptorship programme on turnover rate, cost, quality and professional development. J Clin Nurs. 2009 Apr; 18(8): 12171225. doi: 10.1111/j.1365-2702.2008.02662.x

Lincoln, Y.S. \& Guba, E. G. (1985) Naturalistic Inquiry. CA: Sage Publications, Newbury Park.

Lockhart L. The art of team building. Nursing made Incredibly Easy. 2015; 13(3): 51-52 doi: 10.1097/01.NME.0000462648.19515.8a

McSherry, R, Pearce, P, Grimwood, K \& McSherry, W (2012). The pivotal role of nurse managers, leaders, and educators in enabling excellence in nursing practice. Journal of Nursing Management. 20.7-19. DOI: 10.1111/j.1365-2834.2011.01349.x 